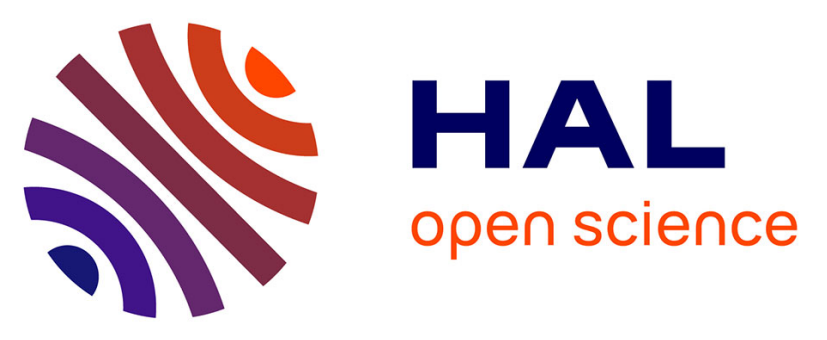

\title{
Adherence to ready-to-use food and acceptability of outpatient nutritional therapy in HIV-infected undernourished Senegalese adolescents: research-based recommendations for routine care
}

Fatou Niasse, Marie Varloteaux, Karim Diop, Sidy Mokhtar Ndiaye, François Niokhor Diouf, Pape Birane Mbodj, Babacar Niang, Aminata Diack, Cecile Cames

\section{- To cite this version:}

Fatou Niasse, Marie Varloteaux, Karim Diop, Sidy Mokhtar Ndiaye, François Niokhor Diouf, et al.. Adherence to ready-to-use food and acceptability of outpatient nutritional therapy in HIV-infected undernourished Senegalese adolescents: research-based recommendations for routine care. BMC Public Health, 2020, 20, pp.695. 10.1186/s12889-020-08798-z . hal-02869840

\author{
HAL Id: hal-02869840 \\ https://hal.science/hal-02869840
}

Submitted on 16 Jun 2020

HAL is a multi-disciplinary open access archive for the deposit and dissemination of scientific research documents, whether they are published or not. The documents may come from teaching and research institutions in France or abroad, or from public or private research centers.
L'archive ouverte pluridisciplinaire HAL, est destinée au dépôt et à la diffusion de documents scientifiques de niveau recherche, publiés ou non, émanant des établissements d'enseignement et de recherche français ou étrangers, des laboratoires publics ou privés. 


\title{
Adherence to ready-to-use food and acceptability of outpatient nutritional therapy in HIV-infected undernourished Senegalese adolescents: research-based recommendations for routine care
}

\author{
Fatou Niasse ${ }^{1 \dagger}$, Marie Varloteaux ${ }^{2 \dagger}$, Karim Diop ${ }^{3,4}$, Sidy Mokhtar Ndiaye ${ }^{3}$, François Niokhor Diouf 5 ,
} Pape Birane Mbodj ${ }^{6}$, Babacar Niang ${ }^{7}$, Aminata Diack ${ }^{7}$ and Cecile Cames ${ }^{2^{*}}$ (D)

\begin{abstract}
Background: Ready-to-use food (RUF) is increasingly used for nutritional therapy in HIV-infected individuals. However, practical guidance advising nutrition care to HIV-infected adolescents is lacking, so that little is known about the acceptability of such therapy in this vulnerable population. This study assesses the overall acceptability and perception of a RUF-based therapy and risk factors associated with sub-optimal RUF intake in HIV-infected undernourished adolescents in Senegal.

Methods: Participants 5 to 18 years of age with acute malnutrition were enrolled in 12 HIV clinics in Senegal. Participants were provided with imported RUF, according to WHO prescription weight- and age-bands (2009), until recovery or for a maximum of 9-12 months. Malnutrition and recovery were defined according to WHO growth standards. Adherence was assessed fortnightly by self-reported RUF intake over the period. Sub-optimal RUF intake was defined as when consumption of the RUF provision was $<50 \%$. RUF therapy acceptability and perceptions were assessed using a structured questionnaire at week 2 and focus group discussions (FGDs) at the end of the study. Factors associated with sub-optimal RUF intake at week 2 were identified using a stepwise logistic regression model.

\footnotetext{
* Correspondence: cecile.cames@irdfr

${ }^{\dagger}$ Fatou Niasse and Marie Varloteaux are first co-authors.

${ }^{2}$ Institut de recherche pour le développement (IRD), UMI233 TransVIHmi,

INSERM U1175, Université de Montpellier, 911 Av Agropolis, 34394

Montpellier, France

Full list of author information is available at the end of the article
}

C C The Author(s). 2020 Open Access This article is licensed under a Creative Commons Attribution 4.0 International License, which permits use, sharing, adaptation, distribution and reproduction in any medium or format, as long as you give appropriate credit to the original author(s) and the source, provide a link to the Creative Commons licence, and indicate if changes were made. The images or other third party material in this article are included in the article's Creative Commons licence, unless indicated otherwise in a credit line to the material. If material is not included in the article's Creative Commons licence and your intended use is not permitted by statutory regulation or exceeds the permitted use, you will need to obtain permission directly from the copyright holder. To view a copy of this licence, visit http://creativecommons.org/licenses/by/4.0/. The Creative Commons Public Domain Dedication waiver (http://creativecommons.org/publicdomain/zero/1.0/) applies to the data made available in this article, unless otherwise stated in a credit line to the data. 
(Continued from previous page)

Results: We enrolled 173 participants, with a median age of 12.5 years (Interquartile range: 9.5-14.9), of whom 61\% recovered from malnutrition within the study period. Median follow-up duration was 66 days (21-224). RUF consumption was stable, varying between 64 and $57 \%$ of the RUF provided, throughout the follow-up. At week 2, sub-optimal RUF intake was observed in 31\% of participants. Dislike of the taste of RUF (aOR $=5.0,95 \%$ Cl: $2.0-12.3$ ), HIV non-disclosure $(5.1,1.9-13.9)$ and food insecurity $(2.8,1.1-7.2)$ were the major risk factors associated with suboptimal RUF intake at week 2. FGDs showed that the need to hide from others to avoid sharing and undesirable effects were other constraints on RUF feeding.

Conclusions: This study revealed several factors reducing the acceptability and adherence to RUF therapy based on WHO guidelines in HIV-infected adolescents. Tailoring prescription guidance and empowering young patients in their care are crucial levers for improving the acceptability of RUF-based therapy in routine care.

Trial registration: ClinicalTrials.gov identifier: NCT03101852, 04/04/2017.

Keywords: Acute malnutrition, Acceptability, Adherence, HIV, Ready-to-use food, Children, Adolescents, Africa

\section{Introduction}

Malnutrition is common among children living in low incomes settings and is even more critical in HIVinfected children, including those on antiretroviral treatment (ART) [1, 2], as HIV infection can induce growth failure and malnutrition in children, which in turn contribute to faster disease progression. Successful treatment of acute malnutrition in young children $<5$ years [3], including HIV-infected children [4-6], has been achieved using Plumpy Nut ${ }^{\circ}$ and Plumpy Sup (Nutriset, Malaunay, France) food supplements, developed for pediatric use and generically referred to as imported ready-to-use food (RUF). During the last decade, most African countries adopted national guidelines for RUFbased treatment of acute malnutrition in children $<5$ years, including those with HIV.

The vulnerabilities of HIV-infected adolescents, especially those with perinatal HIV infection, have been extensively described [7]. They often have more advanced HIV disease with related co-morbidities associated with delayed HIV treatment and lifelong infection [8]. Perinatally HIV-infected children $\geq 5$ years and adolescents are also vulnerable to malnutrition and often face severe forms. Recent studies reported 16 to $33 \%$ of acute malnutrition in children and adolescents 5 to 19 years-old on long term ART, of whom one-third was severely undernourished $[9,10]$. Because National health systems have been oriented towards monitoring and care of children $<5$ years and adult, adolescents health care services, including those living with HIV, suffer from multiple deficiencies, including the lack of nutritional care [11]. Despite World Health Organisation (WHO) recommendations for the integration of nutritional interventions into comprehensive HIV treatment programmes [12], nutritional therapy at HIV treatment sites in subSaharan Africa remains poorly available [13]. This is particularly true with respect to the recommendations for adolescents, 2009 WHO Preliminary guidelines for an integrated approach to the nutritional care of HIVinfected adolescents [14].

Consequently, acceptability data and practical guidance advising the implementation of nutrition care in these vulnerable patients are lacking. This is of concern, as the effectiveness of medical therapy is strongly associated with its level of acceptance, adherence to prescription, timing of intake, and medical and psychosocial surroundings [15], all of which may differ among patients of different age classes. Experimental data on the acceptability of RUF were obtained primarily from studies conducted in adults since RUF provisioning has become a widely used outpatient strategy among vulnerable adults through food-by-prescription programmes. Qualitative studies conducted in Southern Africa reported poor overall acceptability of RUF [16-18], whereas its organoleptic qualities were rated as good in studies from Vietnam [19] and Haiti [20]. Assessment of a pilot nutrition support providing RUF to 43 HIVinfected children and adolescents with acute malnutrition in two HIV clinics in Senegal shown that beneficiaries consumed $50 \%$ of their RUF on average and $20 \%$ defaulted from the programme [21]. Following this pilot study, the SNACS Study was implemented to assess the acceptability, effectiveness, and feasibility of outpatient RUF-based nutritional therapy among HIV-infected children and adolescents presenting with acute malnutrition across Senegal. The intervention protocol followed the 2009 WHO Guidelines [14]. The operational objective of this research, conducted in close partnership with the Senegalese Ministry of Health, was to provide the national HIV programme with evidence-based recommendations for outpatient nutritional therapy in HIVinfected children and adolescents.

The objectives of the present report are first to describe the overall acceptability of the nutritional intervention including perceptions, behaviours, and constraints surrounding RUF use. Secondly, we assess adherence to RUF 
prescription and investigate risk factors associated with sub-optimal intake. To our knowledge, the present study is the first to conduct such assessments among HIVinfected undernourished adolescents.

\section{Methods}

\section{Study setting}

The SNACS study was carried out in Senegal from April 2015 to January 2017 in 12 public paediatric clinics: two in the Dakar district, the capital city, (Albert Royer National Paediatric Hospital and Roi Baudouin Hospital) and 10 in decentralized settings (Regional Hospitals of Saint Louis, Louga, Mbour, Kaoloack, Ziguinchor and Kolda; Health centres of Thiès, Nioro du Rip, Bignona and Kolda). Study implementation was gradual, starting with the central sites in April 2015 and ending with the Kolda sites in March 2016. SNACS, which refers to "snacks", is the French acronym for nutritional support of growing adolescents in Senegal.

\section{Study population and procedures}

The analyses include participants aged 5 to 18 years under active follow-up for their HIV infection and presenting with acute malnutrition. Children with acute malnutrition have low weight for their height due to a rapid weight loss, while those with chronic malnutrition have a low height for their age. Moderate acute malnutrition (MAM) was defined as body mass index-for-age $\mathrm{z}$-score (BMIZ) of $<-2$ and $\geq-3$, and severe acute malnutrition (SAM) as BMIZ $<-3$, according to the WHO growth standards [22]. Participants also were without medical complications and succeeded at an appetite test, which assesses their ability to consume a weightappropriate portion of RUF [23].

Participants were seen every 2 weeks for clinical assessment, provision of RUF for the next 2 weeks, and monitoring of adherence to RUF over the preceding 2 weeks and provided with RUF until they recovered from acute malnutrition (BMIZ $\geq-2$ ), discontinued the study (default, death), and at the latest, until the study was concluded, i.e. 9 months in decentralized clinics or 12 months in Dakar. A social health worker counselled participants and caregivers to distribute RUF intake throughout the day, to eat the RUF in small bites to cope with nausea and lack of appetite, and to have sufficient drinking water at their disposal to prevent diarrhoea. Participants were also advised to avoid RUF intake during mealtimes, in order to preserve family meals and avoid sharing with other family members.

The study used imported RUF, Plumpy $\mathrm{Nut}^{\circ}$ and Plumpy Sup. Both are packaged in a $92 \mathrm{~g}$ individual sachet providing $500 \mathrm{kcal}$ in the form of an energy-dense lipid paste made from peanut butter, oil, sugar and a high vitamin and mineral supplement (the first contains milk powder, while the second contains soy proteins) [24]. Plumpy Sup is recommended in the management of MAM, amongst other options, while Plumpy Nut ${ }^{\circ}$ is dedicated to the treatment of SAM. WHO recommends a Plumpy Nut $^{\circ}$ prescription of 75 to $100 \mathrm{kcal} / \mathrm{kg} / \mathrm{d}$ in children aged 5 to 10 years and 60 to $90 \mathrm{kcal} / \mathrm{kg} / \mathrm{d}$ above that age [14]. Across all ages, Plumpy Sup ${ }^{\circ}$ was prescribed at the lowest recommended dose of $60 \mathrm{kcal} / \mathrm{kg} / \mathrm{d}$ to participants with MAM. Prescription by weight may involve a high daily dose in older HIV-infected children and adolescents. The lowest value was used and maximum energy intake provided by RUF was limited to $2000 \mathrm{kcal} / \mathrm{d}$ i.e. 4 sachets in all participants to preserve habitual diet and prevent appetite saturation.

\section{Data collection and analysis \\ Participants' characteristics at enrolment}

Clinical and therapeutic characteristics of the participant were recorded from medical files while socioeconomic and food security data were collected with the caregiver. The household food insecurity access scale (HFIAS) - a list of nine specific questions about the availability and accessibility of foods and food-related worries for the household during the previous month-was used to assess food insecurity [25]. This access scale generates a 4class variable of food insecurity-none, mild, moderate, and severe. In this analysis, we tested both the 4-class and the derived binary variable (food insecurity: yes vs. none). Minimum dietary diversity was defined as having consumed at least 5 food groups out of 10 the day before the study visit, using the Global Dietary Diversity Indicator for Women, as measured by participant 24 -h recall of food consumption at enrolment and week 2 [26]. The recall was primarily conducted with the participant (with the help of the caregiver if need be).

At week 2, a structured questionnaire covering 5 topics, organoleptic appreciation of RUF, mode of intake, 24-h recall of RUF intake, self-stigma associated to RUF intake and RUF sharing, was administered primarily to participants $\geq 7$ years or caregivers below that age. Questions about RUF sharing were administered separately to participants $\geq 7$ years and caregivers.

\section{Adherence to RUF prescription}

Based on participant and caregiver reports on RUF consumption, adherence was calculated as the percentage of reported RUF sachets consumed out of the number of sachets provided at each follow-up visit. Early sub-optimal RUF intake was defined when this ratio was $<50 \%$ at week 2 .

\section{Risk factors of early sub-optimal RUF intake}

Associations between early sub-optimal RUF intake with socioeconomic and demographic profiles, RUF acceptability 
data, as well as ART drug history and severity of malnutrition, were investigated using univariable regression, after controlling for collinearity, as well as stepwise logistic regression models. Explanatory variables with $P<0.20$ from the univariable analysis were included in the multivariable models and excluded by the stepwise procedure at $P>0.10$. The final set of variables retained were tested for interactions. Differences were considered statistically significant at $P<0.05$. Medians are presented with their interquartile range (IQR). All statistical analyses were performed in SAS, version 9.3 (Cary, North Carolina, USA).

\section{Expectations, perceptions and experiences of participants in the nutritional intervention}

Focus group discussions (FGD) were conducted at the Dakar study clinics, after the end of the total study period (12 months), with a convenience subsample of participants aged at least 7 years, which aimed to be fairly representative of the study population with regards to age, sex and severity of malnutrition. Sessions were conducted in Wolof, the national language of Senegal, or French, by a social health worker and the doctoral student (MV) and focused on (i) participant expectations from the study, (ii) perceptions of RUF and (iii) experiences of the nutritional intervention, depending on their outcome in the study (recovery, failure, default). FGD were audiotaped and transcribed verbatim into French. The thematic analysis which consisted in coding, synthesizing and grouping sections of text from the FGDs that covered similar issues or experiences, was performed by the doctoral student (MV) in Dedoose, version 7.0.21 (Los Angeles, California, USA).

\section{Ethical approval}

Ethics clearance for the SNACS study protocol was given by the Ethics and Regulatory Committee and the Ministry of Health in Senegal. All parents or surrogate caregivers provided written informed consent. Participants aged $\geq 7$ years received extended information about the research and provided verbal assent [27].

\section{Results}

\section{Study population}

From April 2015 to September 2016, the SNACS study enrolled 184 HIV-infected participants of whom 173 were between the ages of 5 and 18 years old (median age: 12.5 years, IQR: 9.5-14.9), 104 presenting with MAM and 69 with SAM, were included in these analyses (Table 1). All but one participant had been infected through mother-to-child transmission. The mother or father was the primary caregiver in 44 and $8 \%$ of participants, respectively, while $48 \%$ lived with a surrogate caregiver who was an ascendant (grandparents, uncles, aunts: $n=24$ ), collateral (siblings, cousins: $n=57$ ), or a neighbour $(n=2)$. Eighty-seven per cent were on ART at enrolment for a median duration of 48 months (15-75). Only $28 \%$ had had their HIV serologic status disclosed for whom the median time since the disclosure was 11 months (5-26). HIV status disclosure was associated with virologic suppression $(<50$ copies $/ \mathrm{ml}, P<0.0001)$. Sixty-one per cent of participants recovered from wasting after a median follow-up duration of 29 days (1665), $31 \%$ failed to reach BMIZ $\geq-2$ during the time of the study, $6 \%$ defaulted and $2 \%$ died. The overall median follow-up duration was 66 days (21-224), which increased from 30 days (16-115) among participants presenting with MAM to 156 days $(85-275)$ in SAM participants $(P<0.0001)$.

\section{Acceptability of RUF and feeding practices at week 2}

Overall, $87,79,85$, and $80 \%$ of participants initially rated the RUF appearance (colour and texture), taste, smell, and mouth feeling, respectively, as good. Those who stated they disliked RUF taste perceived it as too salty $(38 \%)$, too sour $(24 \%)$, too greasy $(24 \%)$ or too sweet (14\%). Participants who disliked the mouth feeling stated it was too pasty $(80 \%)$ or sticky $(20 \%)$. However, up to $30 \%$ reported feeling at some point disgusted by RUF (Table 2), and 19\% stated there had been occasions when they refused to eat it. At least one episode of diarrhoea and/or vomiting related to RUF intake was reported by $30 \%$ of participants at the first follow up visit, 2 weeks after initiating therapy. $24 \%$ of participants presented 1 to 3 episodes of diarrhoea and 12\% presented 1 to 3 episodes of vomiting. The primary mode for eating RUF was directly from the sachet (85\%) (Table 2). Many participants $(63 \%)$ consumed RUF in place of breakfast, while others reported eating it just before (10\%), or just after (12\%) meals. Only 15\% reported consuming RUF as a snack. At enrolment and week 2, 56 and 39\% of participants, respectively, reached the minimum dietary diversity the day before the visit. One-third of the participants stated they hid from others when eating RUF (Table 2). The reasons given were fear of envious reactions $(42 \%)$, arousing pity $(19 \%)$, or teasing $(16 \%)$, while $23 \%$ chose not to respond to the question. Occasional RUF sharing within the household was reported by $38 \%$ of caregivers and participants (Table 2). Caregivers reported that they felt: they (82\%), other adults (53\%), or other children (67\%) in the household needed the RUF. Acceptability data were also compared by the severity of malnutrition and no remarkable association was found.

\section{Adherence to RUF}

Most participants $<12$ years were provided with 2 to 3 RUF sachets daily while most of their older counterparts received 3 to 4 sachets. If the maximum energy intake to 
Table 1 Characteristics of HIV-infected participants and their caregivers at enrolment in the SNACS study, Senegal ${ }^{a-b}$

\begin{tabular}{|c|c|c|c|c|c|c|c|}
\hline \multirow{2}{*}{$\begin{array}{l}\text { Characteristics } \\
\text { Girl }\end{array}$} & \multicolumn{2}{|c|}{$\begin{array}{l}<12 \text { years } \\
N=84\end{array}$} & \multicolumn{2}{|c|}{$\begin{array}{l}\geq 12 \text { years } \\
N=89\end{array}$} & \multicolumn{2}{|c|}{$\begin{array}{l}\text { All } \\
N=173\end{array}$} & \multirow{2}{*}{$\begin{array}{l}P \text { value } \\
0.88\end{array}$} \\
\hline & 34 & (40) & 35 & (39) & 69 & (40) & \\
\hline Decentralized study site & 51 & (61) & 42 & (47) & 93 & (54) & 0.07 \\
\hline Acute malnutrition & & & & & & & 0.04 \\
\hline Moderate & 57 & (68) & 47 & (53) & 104 & (46) & \\
\hline Severe & 27 & (32) & 42 & (47) & 69 & (40) & \\
\hline HAZ, median IQR & -1.7 & $(-2.4--0.8)$ & -2.0 & $(-2.7--1.2)$ & -1.8 & $(-2.6--0.9)$ & 0.09 \\
\hline At school & 58 & (69) & 74 & (83) & 132 & (76) & 0.03 \\
\hline Family status & & & & & & & 0.24 \\
\hline Parents alive & 31 & (37) & 21 & (24) & 52 & (30) & \\
\hline Mother orphan & 20 & (24) & 23 & (26) & 43 & (25) & \\
\hline Father orphan & 16 & (19) & 25 & (28) & 41 & (24) & \\
\hline Double orphan & 17 & (20) & 20 & (22) & 37 & (21) & \\
\hline HIV disclosed & 5 & (6) & 44 & (49) & 49 & (28) & $<0.0001$ \\
\hline$A R T^{c}$ & & & & & & & 0.02 \\
\hline No ART & 17 & (20) & 6 & (7) & 23 & (13) & \\
\hline ART - virologic suppression ${ }^{d}$ & 26 & (31) & 39 & $(44)$ & 65 & (38) & \\
\hline ART - no virologic suppression & 40 & (48) & 43 & (49) & 83 & (49) & \\
\hline CD4 cell $/ \mathrm{mm}^{3}$, median IQR & 603 & $(343-861)$ & 414 & $(209-707)$ & 522 & $(229-780)$ & 0.04 \\
\hline Caregiver school level & & & & & & & 0.28 \\
\hline None & 36 & (43) & 49 & (55) & 85 & (49) & \\
\hline Primary & 25 & (30) & 21 & (24) & 46 & (27) & \\
\hline Secondary and more & 23 & (27) & 19 & (21) & 42 & (24) & \\
\hline Caregiver income & & & & & & & 0.50 \\
\hline None & 40 & (48) & 36 & (40) & 76 & (44) & \\
\hline Regular & 9 & (11) & 14 & (16) & 23 & (13) & \\
\hline Irregular & 35 & $(42)$ & 39 & (44) & 74 & (43) & \\
\hline Food insecure household & 65 & (77) & 68 & (76) & 133 & (77) & 0.88 \\
\hline
\end{tabular}

${ }^{\mathrm{a}}$ Data are $\mathrm{N}, \%$ unless otherwise indicated

${ }^{\mathrm{b}}$ Abbreviations: HAZ height-for-age z-score, IQR interquartile range, ART antiretroviral treatment

'2 missing values

${ }^{d}$ Virologic suppression is defined as viral load $\leq 50$ copies $/ \mathrm{ml}$

be provided by RUF had not been limited to $2000 \mathrm{kcal} / \mathrm{d}$, i.e. 4 sachets per protocol, 15 participants would have been prescribed 5 to 6 sachets according to weight and age prescription bands.

At week 2, 31\% of participants were sub-optimal RUF consumers which means they had consumed less than $50 \%$ of their RUF provision. Only $11 \%$ of participants reported they had consumed all the doses prescribed.

Overall, participants reported having consumed 61\% (45-81) of their RUF at week 2. This proportion was stable (varying between 64 and 57\%) throughout the follow-up among the remaining participants. The energy provided by RUF per kg of body weight was significantly higher in MAM participants than in their SAM counterparts in both age group. However, energy intake from
RUF per kg of body weight was far lower than expected based on the prescription weight bands for all participants; while being significantly higher in the younger participants than in their older counterparts (Table 3).

In both age groups, there was no difference either in proportions of sub-optimal RUF consumers or proportions of RUF intake and energy intake per $\mathrm{kg}$ of body weight according to the severity of malnutrition.

\section{Factors associated with sub-optimal RUF intake}

To identify factors associated with early sub-optimal intake, we ran a stepwise logistic regression model with sub-optimal RUF intake (yes/no) as the dependent variable. Dislike of the taste of RUF $(\mathrm{aOR}=5.0,95 \%$ CI: 2.0 12.3), HIV-non disclosure (5.1, 1.9-13.9) and food 
Table 2 Perceptions and behaviors related to the management of RUF therapy among undernourished HIV-infected participants and their caregiver 2 weeks after enrolment in the SNACS study, Senegal ${ }^{a-b}$

\begin{tabular}{|c|c|c|c|c|c|c|c|}
\hline \multirow{2}{*}{ Caregivers } & \multicolumn{2}{|c|}{$<12$ years } & \multicolumn{2}{|c|}{$\geq 12$ years } & \multicolumn{2}{|l|}{ All } & \multirow[t]{2}{*}{$P$ value } \\
\hline & & & & & & & \\
\hline Responsible for RUF management & & & & & & & $<.0001$ \\
\hline Caregiver & 67 & (81) & 29 & (33) & 96 & $(56)$ & \\
\hline Participant & 16 & (19) & 60 & (67) & 76 & (46) & \\
\hline RUF sharing with caregiver & 25 & (30) & 27 & (30) & 52 & (30) & 0.98 \\
\hline RUF sharing with other adults & 6 & (8) & 6 & (7) & 12 & (7) & 0.83 \\
\hline RUF sharing with other children & 13 & (17) & 11 & (13) & 24 & $(15)$ & 0.42 \\
\hline \multicolumn{8}{|l|}{ Participants $^{c}$} \\
\hline RUF perceived as a drug & & & & & & & 0.006 \\
\hline Yes & 63 & (76) & 83 & (93) & 146 & (85) & \\
\hline No & 8 & (10) & 3 & (3) & 11 & (6) & \\
\hline Don't know & 12 & (14) & 3 & (3) & 15 & $(9)$ & \\
\hline Reason for RUF therapy & & & & & & & 0.0005 \\
\hline Sickness & 20 & (24) & 26 & (30) & 46 & (27) & \\
\hline Malnutrition & 48 & (58) & 62 & (71) & 110 & (64) & \\
\hline Don't know & 15 & (18) & - & - & 15 & (9) & \\
\hline Participant needs encouragement for RUF feeding & 39 & (47) & 33 & (37) & 72 & (42) & 0.19 \\
\hline Participant is disgusted by RUF & 27 & (33) & 24 & (27) & 51 & (30) & 0.42 \\
\hline Participant hides to take RUF & 21 & (25) & 29 & (33) & 50 & (29) & 0.29 \\
\hline Single sachet taken over several intake & 44 & (53) & 36 & (40) & 80 & $(47)$ & 0.10 \\
\hline Main mode of intake & & & & & & & 0.18 \\
\hline Direct feeding from the sachet & 67 & (81) & 79 & (89) & 146 & (85) & \\
\hline Diluted in gruel & 14 & (17) & 10 & (11) & 24 & (14) & \\
\hline Spread on bread & 2 & (2) & - & - & 2 & (1) & \\
\hline
\end{tabular}

${ }^{\mathrm{a}}$ Data are $\mathrm{N}(\%)$

${ }^{\mathrm{b}} R U F$ ready-to-use food

${ }^{c}$ Questions were asked to the participant (and/or to the caregiver if need be when participant $\leq 7$ years)

insecurity $(2.8,1.1-7.2)$ were the major risk factors associated with early sub-optimal RUF intake (Table 4). There was no association between food insecurity and RUF taste appreciation, however, there was a significant interaction between these two variables in the multivariable model $(p=0.001)$. Stratified analysis indicated that in the absence of food insecurity, proportions of sub-optimal consumers were similar whatever the RUF taste appreciation (Mantel-Haenszel Chi2 test probability $=0.36$ ), while in food-insecure households, dislike of the taste of RUF was strongly associated with a sub-optimal intake $(p<0.0001)$.

\section{Expectations, perceptions and experiences of participants} in the nutritional intervention

The qualitative analysis involved a convenience subsample of 24 participants in Dakar of whom 9 were girls and 8 were enrolled as SAM (Table 5). Four FGDs were

Table 3 Adherence to RUF among HIV-infected participants 2 weeks after enrolment in the SNACS study, Senegal ${ }^{a-b}$

\begin{tabular}{|c|c|c|c|c|c|}
\hline \multirow{2}{*}{$\begin{array}{l}\text { Indicators } \\
\text { Sub-optimal RUF consumers, N (\%) }\end{array}$} & \multicolumn{2}{|c|}{$\begin{array}{l}<12 \text { years } \\
N=84\end{array}$} & \multicolumn{2}{|c|}{$\begin{array}{l}\geq 12 \text { years } \\
N=89\end{array}$} & \multirow{2}{*}{$\begin{array}{l}P \text {-Value } \\
0.46\end{array}$} \\
\hline & 24 & (29) & 30 & (34) & \\
\hline$\%$ of RUF intake/provided & 64 & $(46-90)$ & 58 & $(42-74)$ & 0.07 \\
\hline Energy provided $/ \mathrm{Kg}$ of BW, Kcal/kg/d & 61 & $(55-68)$ & 55 & $(51-61)$ & $<0.0001$ \\
\hline Energy intake/Kg of BW, Kcal/kg/d & 39 & $(29-50)$ & 31 & $(23-41)$ & 0.001 \\
\hline
\end{tabular}

${ }^{\mathrm{a}}$ Data are median (IQR) unless otherwise indicated

${ }^{\mathrm{b}}$ Abbreviations: RUF ready-to-use food, $B W$ body weight 
Table 4 Risk factors associated with sub-optimal RUF intake in HIV-infected participants 2 weeks after enrolment in the SNACS Study. ${ }^{a-b-c}$, Senegal

\begin{tabular}{|c|c|c|c|c|c|c|}
\hline \multirow[t]{2}{*}{ Effects } & \multicolumn{3}{|c|}{ Univariable analysis } & \multicolumn{3}{|c|}{ Multivariable analysis } \\
\hline & OR & $95 \% \mathrm{Cl}$ & $P$ value & $\mathrm{aOR}$ & $95 \% \mathrm{Cl}$ & $P$ value \\
\hline Girls vs. boys & 1.7 & $0.9-3.2$ & 0.09 & - & - & - \\
\hline$<12$ years vs $\geq 12$ years & 1.2 & $0.6-2.2$ & 0.60 & 0.7 & $0.3-1.5$ & 0.38 \\
\hline Decentralized setting vs Dakar & 2.6 & $1.4-5.0$ & 0.003 & - & - & - \\
\hline \multicolumn{7}{|l|}{ School level } \\
\hline None vs. secondary & 3.5 & $1.0-12.0$ & 0.05 & - & - & - \\
\hline Primary vs. secondary & 1.8 & $0.5-5.8$ & 0.36 & - & - & - \\
\hline HIV status undisclosed: yes vs. no & 4.9 & $2.1-11.2$ & 0.0002 & 5.1 & $1.9-13.9$ & 0.002 \\
\hline Food insecurity: yes vs. no & 2.8 & $1.2-6.3$ & 0.01 & 2.8 & $1.1-7.2$ & 0.03 \\
\hline Disliking RUF taste: yes vs. no & 3.6 & $1.7-7.8$ & 0.001 & 5.0 & $2.0-12.3$ & $<0.001$ \\
\hline Disliking RUF taste * Food insecurity & - & - & - & - & - & 0.001 \\
\hline Caregiver responsible for RUF management vs. participant & 2.2 & $1.1-4.1$ & 0.02 & - & - & - \\
\hline Participant needs encouragement to eat the RUF: yes vs. no & 2.0 & $1.0-3.6$ & 0.04 & - & - & - \\
\hline Participant eats RUF in several vs. single feeding & 1.8 & $1.0-3.3$ & 0.06 & - & - & - \\
\hline SAM vs. MAM & 1.9 & $1.0-3.5$ & 0.05 & - & - & - \\
\hline Virologic suppression ${ }^{\text {d: }}$ no vs. yes & 2.4 & $1.2-4.6$ & 0.01 & 2.0 & $0.9-4.4$ & 0.07 \\
\hline
\end{tabular}

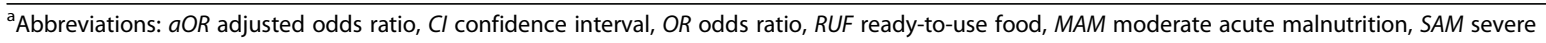
acute malnutrition

bSub-optimal RUF intake is defined as if $<50 \%$ of RUF provided

'Explanatory variables are included at $P<0.20$ in multivariate analysis, exited at $P \geq 0.10$

${ }^{d}$ Virologic suppression is defined as viral load $\leq 50$ copies $/ \mathrm{ml}$

conducted: two FGDs with participants who recovered within the study (one group with HIV-disclosed and one group with HIV-undisclosed participants), one in each Dakar study site and two FGDs with those who failed or defaulted using the same format. Discussions last $1 \mathrm{~h} 30$ on average. FGDs revealed that all the participants had

Table 5 Characteristics of HIV-infected participants included in the focus group discussions in the SNACS study, Senegal ${ }^{a}$

\begin{tabular}{ll}
\hline Characteristics & Participants \\
& $N=24$ \\
\hline Girl & 9 \\
Median age, year (min - max) & $13.7(7.4-17)$ \\
Acute malnutrition at enrollment & \\
$\quad$ Moderate & 16 \\
$\quad$ Severe & 8 \\
At school & 20 \\
Mother orphan & 13 \\
HIV disclosed & 15 \\
On ART & 20 \\
Outcome & \\
Recovery & 12 \\
Failure & 8 \\
Default & 4 \\
\hline
\end{tabular}

${ }^{\mathrm{a}}$ Data are $\mathrm{N}$, unless otherwise indicated similar expectations of the therapy. They were very concerned about their physical appearance, associating their thinness with being short and weak. The SAM participants reported they had been frequently left out of school sports programmes or street football games due to their poor fitness. Participants expressed their strong motivation to gain weight when they started the study. Those who recovered from wasting demonstrated satisfaction and pride in having gained weight. Since youths generally define themselves through the eyes of others, they also perceived the signs of their body shape's normalization in friends' comments: 'People tell me I've got big now! Big as a baobab tree! That I've got stronger and have calf muscles! That I've got more muscle!' Boy, 9 years, HIV-undisclosed, recovery.

Most participants reported that those around them were not told that they were participating in a nutrition intervention; a strategy recommended by health workers to avoid RUF sharing. Managing the daily intake of RUF out of sight proved complicated in homes - sometimes polygamous - where there is practically no space for young people; in particular for boys, to have some privacy: 'I used to hide on the roof terrace to eat (RUF) because I've got a little brother who spends the day asking questions about everything he sees. If I don't give him some he tells his mother and she tells me to give him some.' Boy, 12 years, HIV-disclosed, recovery. This daily effort by 
participants and caregivers to conceal consumption of RUF, however, is not always enough to avoid the sometimes necessary intra-familial sharing: 'My grandfather takes some from me, and sometimes he takes a lot. One day 12 sachets went missing.' Boy, 16 years, HIVundisclosed, failure, as well as extra-familial sharing, which is sometimes deliberate: 'My friends used to ask me to give them some. I used to steal them from my grandmother's bedroom and I hid them like that (he gestures) and I used to give some outside.' Boy, 11 years, HIVdisclosed, recovery.

This secrecy, also motivated by the desire to divert friends' curiosity and comments; even from wellmeaning adults shows the secrecy that surrounds HIV infection and taking ARV: 'My friends used to ask me what I was taking. I didn't tell them anything. You want to know my secret but I'm not going to say - because I can't say!' Boy, 14 years, HIV-disclosed, recovery. 'Sometimes I meet people who tell me I've got bigger but I don't tell them anything. I don't want them to ask me.' Boy, 8 years, HIV-undisclosed, failure.

Close follow-up visits at the hospital affected participants badly, worried that these repeated absences might arouse suspicion at school: It used to bother me because I was absent too often. In the end, my classmates used to ask me what I had; sometimes it was my teachers. Only my teaching assistant knew that I was sick. It was my mother who went there. I don't really know what she told them. My classmates used to ask me all the time why I was going to the hospital. I used to change the subject.' Girl, 16 years, HIV-disclosed, recovery. Repeated absences could sometimes disrupt following classes and learning: I lost marks because of my absences. Our lessons are long and catching up classes is complicated. It's difficult to re-copy notes. It makes me tired.' Boy, 12 years, HIV-disclosed, default.

The main divergence observed between participants who recovered and those who did not concerned the perception of RUF. The disgust of RUF, occurring early on or overtime, was a major constraint to RUF adherence: 'We have an illness [HIV-infection] and on top of that we have malnutrition. My friends are well-built; more than me. I feel that I'm malnourished and I am until now. At the start, I wanted it [RUF]. I forced myself; I used to take four (sachets) per day. I even liked it but over time it was the smell. It disgusted me.' Boy, 16 years, HIV-disclosed, default.

Nausea, diarrhoea and vomiting whilst taking RUF were most often reported by unsuccessful participants for whom this represented a huge obstacle: 'The doctor asked me why I wasn't putting on any weight. I told him every time I ate some I felt I was going to vomit. He said 'Oh really?' I replied yes. It was me that decided to give up.' Girl, 8 years, HIV-undisclosed, failure.
Participants who recovered reported the various strategies they implemented to cope with the growing fatigue they felt in adhering to the RUF prescription, which consisted in alternating between modes of intake, or for some of the oldest, to allow themselves to have breaks of one to 2 days in RUF feeding. One participant, although affected by the study constraints, reorganized his daily routine around visits to the clinic and RUF feeding: 'I had to take three and I set the times: at 7:30 am I used to get up and take it. At 12:30 pm I used to leave the room to go into the bedroom. At 7:30 pm I used to go into the bedroom, heat the water, cut [the RUF] in the cup with water. I'd stir it and drink it. I think about my health and growth above all. I've got used to it.' Boy, 13 years, HIV-disclosed, recovery.

\section{Discussion}

Most participants initially reported a positive organoleptic appreciation of RUF. However, from the earliest weeks of the study, many of them needed encouragement from the caregiver for continued RUF feeding, and feelings of disgust were common. On average, participants reported having consumed two-third of their provision throughout the study, despite the adjustments made to reduce the recommended prescription. The rationale of the WHO prescription weight bands refers to an increase in the recommended nutritional intake levels for asymptomatic and malnourished HIV-infected people, which could reach 50 to $100 \%$ of energy needs in children [28]. The RUF is thus expected to provide a complete diet to a child with SAM with, in replacement of the habitual household diet, and cover additional energy needs due to HIV-infection [14]. Our results suggest that age- and weight-based prescription bands might have overestimated adolescents' ability to consume RUF in "real life" and that there might be a threshold of RUF intake that some individuals cannot overcome due to nutritional density and sticky composition. Indeed, except for a few studies which proposed 2 sachets daily over short durations, in which HIV-adults stated that they appreciated RUF $[19,20]$ or adapted to the taste after the first weeks [29], a leading reason for non-adherence was disgust and growing tired of having to consume 3 to 4 sachets per day over a long time [16-18].

At week 2, 31\% of participants reported having consumed less than half of the RUF provided. Not surprising, disliking the taste of the RUF was associated with sub-optimal RUF intake. This observation is consistent with studies involving HIV-infected adults reporting that many disliked the RUF taste and smell and that RUF taste and consistency made it difficult to swallow [17, $18,29,30]$. Food insecurity is known as a major factor of poor adherence to food-by-prescription programmes as individuals are unlikely to refuse food ration sharing. 
Interestingly, stratified analyses showed that participants disliking RUF were more likely to present sub-optimal intake when they lived in food-insecure rather than in food-secure households. In case of participant reluctance, caregiver commitment to support RUF feeding might have been lower in the most vulnerable families, which thus encouraged sharing. The absence of association between sharing and sub-optimal intake could suggest that merely occasional sharing, perceived as acceptable, was reported. Group discussions with adolescents also suggest that some sharing escaped the attention of the caregivers.

We found HIV-non disclosure to be associated with sub-optimal RUF intake. This finding echoes our recent analysis in the same cohort reporting that HIV-disclosed participants showed a better understanding of the research information at enrolment in the present study [27]. Disease disclosure proceeds together with a better understanding of therapeutic issues, such as the importance of adherence to medication [31]. Such empowerment might have similarly benefited the early adherence to nutritional intervention.

The only other study which assessed similar support based on Plumpy $\mathrm{Nut}^{\circ}$ among children and adolescents, conducted in an HIV clinic in Mali, reported greater adherence figures as $88 \%$ of participants were rated as "good" RUF consumers [32]. Comparisons between the two studies are however limited as they differ in prescription procedures. Also, the Malian study did not explore RUF sharing practice and acceptability of nutrition therapy and enrolled younger participants $(<15$ years) with less severe acute malnutrition than we did.

The high prevalence of undesirable effects (nausea, vomiting and diarrhoea) attributed to RUF in this study is of concern as it hindered RUF acceptability and adherence in some participants. Qualitative studies also report similar undesirable effects attributed to RUF in adults on ART or starting ART and pregnant women [16, 17, 30]. In some of these patients, the initial undesirable effects were transient and attributed to pregnancy or drugs initiation. RUF feeding advice provided by the study staff, although partially followed, are questionable as they may not have been feasible in practice: for example to distribute RUF intake throughout the day and avoid mealtime. Many participants used to hide from others when eating RUF, most of the time in the caregiver' bedroom, primarily to avoid being asked to share. Limited time to eat the RUF due to school and transportation and space constraints in the household combine to hinder the integration of feeding therapy into the usual food practices. In addition, many participants substituted their habitual breakfast with RUF or ate it at mealtime, with possible negative impacts on the dietary diversity provided by family meals. All in all, these constraints on RUF intake contribute to appetite saturation and decreased adherence.

This study has several limitations. First, the validity of information about both adherence and sharing practices is generally difficult to ensure, as some degree of socially desirable response bias might be expected. Counting the RUF sachets would have been a reliable method to confirm participants' reports, but the pilot study showed little compliance with the instruction among participants and caregivers to return with unused sachets at each visit. Based on our mixed data analyses, we hypothesize that some participants' reluctance to eat the RUF might have resulted in consistent family sharing, rather than regular sharing which would have reduced RUF feeding. Second, although RUF adherence data were computed at each follow-up point, we considered only the first 2 weeks of consumption to run the risk factors analyses. Early RUF adherence, while participants went through an adaptation phase, might not be representative of the overall RUF consumption. However, this methodological choice is justified for several reasons: (i) this avoided analytical bias due to cohort attrition (the first recoveries and defaults occurred at week 2), (ii) as in other studies [21, 32], adherence to RUF was rather stable over time among the remaining participants, (iii) adherence data coincide with acceptability data collected once at week 2 . Third, we recruited participants in Dakar for the FGDs as these central sites have a longstanding and routine practice of hosting discussion groups as part of follow-up for older children and adolescents. By contrast, the regional sites had no comparable experience or practices. Although FGDs results may not be generalizable to all children and adolescents in Senegal, they highlight perceptions, behaviours, and constraints surrounding RUF use that are likely to be very similar in decentralized settings. Last, attendance at follow-up visits was demanding for our participants. However, because of our providing remuneration for travel costs, we documented very few missed or delayed visits. Attendance to follow-up visit and continuity of RUF provision might need specific attention in the routine care.

Palatability of imported RUF constitutes a major constraint for the acceptability of nutritional therapy. Studies comparing the acceptability of a novel and local product versus imported RUF (Plumpy Nut ${ }^{\circ}$ ) in HIVinfected or uninfected populations could not demonstrate the superiority of this alternative product so far $[19,33,34]$. Imported RUF is expected to remain by far the most widely used and easily available products for outpatient therapy. Therefore, an alternative lever for improving the acceptability of RUF therapy in routine care is to improve follow-up and support procedures.

The socially and physiologically acceptable RUF intake could be assessed with the young patient, and possibly 
adjusted during therapy according to their progression and tolerance. It would also facilitate increasing the time between follow-up visits to monthly or every other month since adolescents would not be given considerable RUF provision.

Compared to other age groups, HIV-infected adolescents exhibit higher rates of loss to follow up [35, 36], poor ART adherence [37, 38], and increased needs for psychosocial support [39]. Nutritional rehabilitation is thus an additional challenge to routine HIV care that requires adequate counselling and continuous support to ensure adherence, including preventing or lessening undesirable effects. Particular attention should be paid to adolescents with SAM - who were also older in this cohort- as they are likely to experience longer follow-up duration. This might lead to saturation and discouragement and strongly affect adherence to RUF-based protocols. Strengthening HIV clinic capacity and adolescent empowerment, through peer and community support and early HIV-disclosure process, could benefit nutritional interventions and improve the acceptability of RUF therapy.

Food-by-prescription is mostly used to focus on HIVrelated wasting. Our study did not distribute food for the entire family to complement individual-targeted RUF therapy. Strategies to reduce sharing such as the rationalization of RUF prescription suggested above, the enrolment of other undernourished family members in RUF therapy, together with food complements for the household need to be evaluated.

\section{Conclusion}

This study conducted at the national level in Senegal highlights several acceptability issues of RUF therapy based on WHO guidelines in HIV-infected children and adolescents, which may lead to decreasing adherence to therapy protocols. Beyond the initial barrier of RUF taste in some participants, the main factors affecting adherence were closely related to RUF feeding constraints and HIV non-disclosure. There is an urgent need for differentiated approaches to address specific health and nutritional needs of HIV-infected adolescents. Tailoring prescription guidance, empowering young patients in their care are and innovating in how to more effectively support them in their nutritional therapy are crucial levers for improving acceptability of RUF-based therapy in routine care. As such, our findings are valuable in informing improved management of nutritional care in this vulnerable population.

\section{Abbreviations}

ART: Antiretroviral treatment; BMIZ: Body mass index z-score (for age and sex): FGD: Focus group discussion; IQR: Interquartile range; MAM: Moderate acute malnutrition; RUF: Ready-to-use food; SAM: Severe acute malnutrition

\section{Acknowledgements}

The authors gratefully acknowledge all the participating children and their caregivers. They sincerely thank David Masson for his valuable advice and input during the conduct of the study. They thank all the clinics' staff who participated in the study:

(1) Centre Hospitalier National d'Enfants Albert Royer de Dakar (Senegal): Aminata Diack (associated investigator), Aicha Dia, Babacar Niang (study clinicians); Ndeye Ngone Have, Astou Dieye, Khady Sidibe (social workers); Oumy Fall (nurse):

(2) Hospital Roi Baudouin de Guediawaye (Senegal): Baly Ouattara (study clinician); Abdou Kader Niang (nurse); Alhadji Bassine Diom, Adama Ndour, Lamine Mohamed Souane (social workers);

(3) Centre hospitalier régional de Saint-Louis (Senegal): Justine Ngom (study clinician); Ndéye Fatou Diédhiou (social worker), Ndéye Penda Yade (laboratory);

(4) Centre hospitalier régional de Louga (Senegal): Georges Antoine BAZOLO (study clinician), Georgette Badji, Fatou Tanon (social worker), Cheikh Mbacké Gueye (laboratory);

(5) Centre hospitalier régional de Mbour (Senegal): Abdoul Magib Cissé (study clinician), Ismaila Camara (social worker), Made Masséne Séne (laboratory);

(6) Centre hospitalier régional de Kaolack (Senegal): Papa Birane Mbodj (study clinician), Issakha Camara (social worker), Maimounatou Diallo (nurse), Sérigne Modou Séne (laboratory);

(7) Centre hospitalier régional de Ziguinchor (Senegal): François Niokhor Diouf (study clinician), Pascal Faye (social worker), Mame Thiaré Sarr (laboratory);

(8) Centre hospitalier régional de Kolda (Senegal): Daouda Djiba (study clinician), Gabriel Diombraise Diatta, Kadiatou Diallo (social workers), Jules Beckenbauer Diatta (laboratory);

(9) Centre de santé de Thiès (Senegal): Ousmane Junior Dieng (study clinician), Daya Diallo (social worker), Bassine Ka (laboratory);

(10) Centre de santé de Nioro du Rip (Senegal): Christophe Kanfom (study clinician), Aliou Diallo, Khadidiatou Ba (social workers), Cheikh Ndiaye (laboratory);

(11) Centre de santé de Bignona (Senegal): Ibrahima Tito Tamba (study clinician), Yaya Diédhiou, Béya Aïssatou Coly (social workers), Bintou Diédhiou (nurse), Néné Diatta (laboratory);

(12) Centre de santé de Kolda (Senegal): Thierno Cherif Sy (study clinician), Mahamady Souané, Kamissa Ba (social workers), Oumy Ndiaye (nurse), Antoine Ndiaye (laboratory);

\section{Authors' contributions}

$\mathrm{CC}$ and $\mathrm{FN}$ formulated the research question and designed the study; $\mathrm{KD}$, SMD, AD and MV implemented the study; AD, FND, PBM and SMD collected and monitored the data; CC and MV performed the analyses; CC, MV and FN wrote the first draft of the manuscript. All authors read and commented on drafts and approved the final version of the manuscript.

\section{Funding}

Financial support was provided by Expertise France - Initiative $5 p c$ of the Global Fund and Sidaction. The United Nations Child's Fund and the World Food Programme country offices in Senegal provided Plumpy Nut ${ }^{\oplus}$ and Plumpy Sup ${ }^{\oplus}$, respectively, within the study. MV received a fellowship for her $\mathrm{PhD}$ thesis from Agence Nationale de Recherche sur le SIDA et les hépatites virales (ANRS). Supporting institutions had any part in the study design, analysis or writing of this manuscript.

\section{Availability of data and materials}

The datasets generated and/or analyzed during the current study are available from the corresponding author on reasonable request.

\section{Ethics approval and consent to participate}

Ethics clearance for the SNACS study protocol was given by the Ethics and Regulatory Committee and the Ministry of Health in Senegal. All parents or surrogate caregivers provided written informed consent. Participants aged $\geq 7$ years received extended information about the research and provided verbal assent. 


\section{Competing interests}

The authors declare no competing interests.

\section{Author details}

'Comité national de lutte contre le sida (CNLS), Dakar, Sénégal. ${ }^{2}$ Institut de recherche pour le développement (IRD), UMI233 TransVIHmi, INSERM U1175, Université de Montpellier, 911 Av Agropolis, 34394 Montpellier, France. ${ }^{3}$ Centre régional de recherche et de formation à la prise en charge clinique (CRCF), Dakar, Sénégal. ${ }^{4}$ Division de lutte contre le sida et les infections sexuellement transmissibles (DLSI), Ministère de la santé et de l'action sociale, Dakar, Sénégal. ${ }^{5}$ Centre hospitalier régional, Ziguinchor, Sénégal. ${ }^{6} \mathrm{Centre}$ hospitalier régional, Kaolack, Sénégal. ${ }^{7}$ Centre Hospitalier National Universitaire d'Enfants Albert Royer, Dakar, Sénégal.

\section{Received: 2 December 2019 Accepted: 28 April 2020} Published online: 15 May 2020

\section{References}

1. Gsponer T, Weigel R, Davies MA, Bolton C, Moultrie H, Vaz P, et al. Variability of growth in children starting antiretroviral treatment in southern Africa. Pediatrics. 2012;130(4):e966-77.

2. Weigel R, Phiri S, Chiputula F, Gumulira J, Brinkhof M, Gsponer T, et al. Growth response to antiretroviral treatment in HIV-infected children: a cohort study from Lilongwe, Malawi. Trop Med Int Health. 2010;15(8):93444

3. WHO. Community-based management of severe acute malnutrition. A Joint Statement by the World Health Organization, the World Food Programme, the United Nations System Standing Committee on Nutrition and the United Nations Children's Fund. Geneva: World Health Organization; 2007.

4. Fergusson P, Chinkhumba J, Grijalva-Eternod C, Banda T, Mkangama C, Tomkins A. Nutritional recovery in HIV-infected and HIV-uninfected children with severe acute malnutrition. Arch Dis Child. 2009;94(7):512-6.

5. Sadler K, Kerac M, Collins S, Khengere H, Nesbitt A. Improving the management of severe acute malnutrition in an area of high HIV prevalence. J Trop Pediatr. 2008:54(6):364-9.

6. Sunguya BF, Poudel KC, Mlunde LB, Otsuka K, Yasuoka J, Urassa DP, et al, Ready to use therapeutic foods (RUTF) improves undernutrition among ART-treated, HIV-positive children in Dar Es Salaam, Tanzania. Nutr J. 2012; 11:60.

7. Lowenthal ED, Bakeera-Kitaka S, Marukutira T, Chapman J, Goldrath K, Ferrand RA. Perinatally acquired HIV infection in adolescents from subSaharan Africa: a review of emerging challenges. Lancet Infect Dis. 2014; 14(7):627-39.

8. Sohn $A H$, Hazra R. Old problems for new providers: managing the Postpediatric HIV generation. Clin Infect Dis. 2017;64(8):1113-4.

9. Cames C, Pascal L, Diack A, Mbodj H, Ouattara B, Diagne NR, et al. Risk factors for growth retardation in HIV-infected Senegalese children on antiretroviral treatment: the ANRS 12279 MAGGSEN pediatric cohort study Pediatr Infect Dis J. 2017;36(4):e87-92

10. Jesson J, Masson D, Adonon A, Tran C, Habarugira C, Zio R, et al. Prevalence of malnutrition among HIV-infected children in central and west-African HIV-care programmes supported by the growing up Programme in 2011: a cross-sectional study. BMC Infect Dis. 2015;15:216.

11. WHO. Report of the consultation on the treatment of HIV among adolescents. Geneva: World Health Organization; 2014.

12. WHO. Essential prevention and care interventions for adults and adolescents living with HIV in resource-limited settings. Geneva: World Health Organization; 2008.

13. Anema A, Zhang W, Wu Y, Elul B, Weiser SD, Hogg RS, et al. Availability of nutritional support services in HIV care and treatment sites in sub-Saharan African countries. Public Health Nutr. 2012;15(5):938-47.

14. WHO. Guidelines for an integrated approach to the nutritional care of HIVinfected children (6 months-14 years). Preliminary version for country introduction. Geneva: World Health Organization; 2009

15. Cavaleri MA, Kalogerogiannis K, McKay MM, Vitale L, Levi E, Jones S, et al. Barriers to HIV care: an exploration of the complexities that influence engagement in and utilization of treatment. Soc Work Health Care. 2010; 49(10):934-45

16. Ali E, Zachariah R, Shams Z, Manzi M, Akter T, Alders $P$, et al. Peanut-based ready-to-use therapeutic food: how acceptable and tolerated is it among malnourished pregnant and lactating women in Bangladesh? Matern Child Nutr. 2015;11(4):1028-35.

17. Dibari F, Bahwere P, Le Gall I, Guerrero S, Mwaniki D, Seal A. A qualitative investigation of adherence to nutritional therapy in malnourished adult AIDS patients in Kenya. Public Health Nutr. 2011;15(2):316-23.

18. Kebede MA, Haidar J. Factors influencing adherence to the food by prescription program among adult HIV positive patients in Addis Ababa, Ethiopia: a facility-based, cross-sectional study. Infect Dis Poverty. 2014;3:20.

19. Brown M, Nga TT, Hoang MA, Maalouf-Manasseh Z, Hammond W, Thuc TM, et al. Acceptability of two ready-to-use therapeutic foods by HIV-positive patients in Vietnam. Food Nutr Bull. 2015;36(2):102-10.

20. Beckett AG, Humphries D, Jerome JG, Teng JE, Ulysse P, Ivers LC. Acceptability and use of ready-to-use supplementary food compared to corn-soy blend as a targeted ration in an HIV program in rural Haiti: a qualitative study. AIDS Res Ther. 2016:13:11.

21. Cames C, Varloteaux M, Have NN, Diom AB, Msellati P, Mbaye N, et al. Acceptability of outpatient ready-to-use food-based protocols in HIVinfected Senegalese children and adolescents within the MAGGSEN cohort study. Food Nutr Bull. 2016:38(1):27-36.

22. WHO. WHO child growth standards : length/height-for-age, weight-for-age, weight-for-length, weight-for-height and body mass index-for-age : methods and development. Geneva: World Health Organization; 2006.

23. WHO. Guideline: Updates on the management of severe acute malnutrition in infants and children. Geneva: World Health Organization; 2013.

24. Nutriset. Nutritional Solutions' References Malaunay, France: Nutriset; [cited 2015 1s2/10/2015]. Available from: http://www.nutriset.fr/en/product-range/ scientific-litterature/nutritional-solutions-references.html.

25. Coates J, Swindale A, Bilinsky P. Household food insecurity access scale (HFIAS) for measurement of household food access: Indicator guide (v. 3). Washington, D.C: Food and Nutrition Technical Assistance Project, Academy for Educational Development; 2007.

26. FAO. Introducing the minimum dietary diversity - women (MDD-W) global dietary diversity Indicator for women. Roma: Food and Agriculture Organization; 2014.

27. Hejoaka F, Varloteaux M, Desclaux-Sall C, Ndiaye SM, Diop K, Diack A, et al. Improving the informed consent process among HIV-infected undisclosed minors participating in a biomedical research: insights from the multicentre nutritional SNACS study in Senegal. Tropical Med Int Health. 2019;24(3):294303.

28. WHO. Nutrient requirements for people living with HIV/AIDS: report of a technical consultation. Geneva: World Health Organization; 2003.

29. Olsen MF, Tesfaye M, Kaestel P, Friis H, Holm L. Use, perceptions, and acceptability of a ready-to-use supplementary food among adult HIV patients initiating antiretroviral treatment: a qualitative study in Ethiopia. Patient Prefer Adherence. 2013;7:481-8.

30. Hussein S, Worku A, Aklilu A, Abate K. Ready-to-use therapeutic food for Management of Wasting in HIV infected adults: a qualitative investigation of views and experiences of patients in Ethiopia. Int J Nutr Food Sci. 2015;4(5): 518-29.

31. Nichols J, Steinmetz A, Paintsil E. Impact of HIV-status disclosure on adherence to antiretroviral therapy among HIV-infected children in resource-limited settings: a systematic review. AIDS Behav. 2017;21(1):59-69.

32. Jesson J, Coulibaly A, Sylla M, N'Diaye C, Dicko F, Masson D, et al. Evaluation of a nutritional support intervention in malnourished HIV-infected children in Bamako, Mali. J Acquir Immune Defic Syndr. 2017;76(2):149-57.

33. Dibari F, Bahwere $P$, Huerga $H$, Irena AH, Owino V, Collins $S$, et al. Development of a cross-over randomized trial method to determine the acceptability and safety of novel ready-to-use therapeutic foods. Nutrition. 2013;29(1):107-12

34. Owino VO, Irena AH, Dibari F, Collins S. Development and acceptability of a novel milk-free soybean-maize-sorghum ready-to-use therapeutic food (SMS-RUTF) based on industrial extrusion cooking process. Matern Child Nutr. 2014;10(1):126-34.

35. Auld AF, Agolory SG, Shiraishi RW, Wabwire-Mangen F, Kwesigabo G, Mulenga $\mathrm{M}$, et al. Antiretroviral therapy enrollment characteristics and outcomes among HIV-infected adolescents and young adults compared with older adults--seven African countries, 2004-2013. MMWR Morb Mortal Wkly Rep. 2014;63(47):1097-103.

36. Lamb MR, Fayorsey R, Nuwagaba-Biribonwoha H, Viola V, Mutabazi V, Alwar T, et al. High attrition before and after ART initiation among youth (15-24 years of age) enrolled in HIV care. AIDS. 2014;28(4):559-68. 
37. Fokam J, Sosso SM, Yagai B, Billong SC, Djubgang Mbadie RE, Kamgaing Simo R, et al. Viral suppression in adults, adolescents and children receiving antiretroviral therapy in Cameroon: adolescents at high risk of virological failure in the era of "test and treat". AIDS Res Ther. 2019;16(1):36.

38. Nachega JB, Hislop M, Nguyen H, Dowdy DW, Chaisson RE, Regensberg L, et al. Antiretroviral therapy adherence, virologic and immunologic outcomes in adolescents compared with adults in southern Africa. J Acquir Immune Defic Syndr. 2009;51(1):65-71.

39. Denison JA, Banda H, Dennis AC, Packer C, Nyambe N, Stalter RM, et al. "the sky is the limit": adhering to antiretroviral therapy and HIV self-management from the perspectives of adolescents living with HIV and their adult caregivers. J Int AIDS Soc. 2015;18:19358.

\section{Publisher's Note}

Springer Nature remains neutral with regard to jurisdictional claims in published maps and institutional affiliations.

Ready to submit your research? Choose BMC and benefit from:

- fast, convenient online submission

- thorough peer review by experienced researchers in your field

- rapid publication on acceptance

- support for research data, including large and complex data types

- gold Open Access which fosters wider collaboration and increased citations

- maximum visibility for your research: over $100 \mathrm{M}$ website views per year

At BMC, research is always in progress.

Learn more biomedcentral.com/submissions 